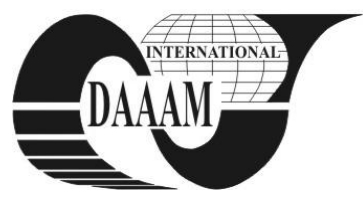

Annals of DAAAM for 2011 \& Proceedings of the 22nd International DAAAM Symposium, Volume 22, No. 1, ISSN 1726-9679 ISBN 978-3-901509-83-4, Editor B. Katalinic, Published by DAAAM International, Vienna, Austria, EU, 2011 Make Harmony between Technology and Nature, and Your Mind will Fly Free as a Bird

\title{
MICROHARDNESS EVALUATION OF STEEL EN S233J2G3 IN HEAT AFFECTED ZONE AFTER PLASMA ARC CUTTING
}

\author{
SIMKULET, V[ladimir]; HATALA, M[ichal]; ORLOVSKY, I[mrich]; ZAJAC, J[ozef]; MONKA, P[eter] \& \\ MICHALIK, P[eter]
}

\begin{abstract}
Plasma cutting belong to progressive and accurate technology of cutting the materials in engineering industry. The article deals with technology of thermal cutting material with plasma arc. In the first part it is addicted to theoretical knowledge of the principle of cutting with plasma arc and current use of the technology in industry. The cut of products of this technology is perpendicular and accurate but using of this technology affects microstructural changes and depth of the heat affected zone (HAZ). The heat used for cutting of material affects its microstructure changes
\end{abstract}

Key words: plasma cutting, microhardness, cut quality

\section{INTRODUCTION}

Plasma Arc Cutting is a process where an open arc can be constricted by passing through a small nozzle, from the electrode to the workpiece. The gas used is typically air and it combines with an electrical current to create a high temperature plasma arc. When placed in contact with an electrically conductive material,the arc passes through the metal, melting a thin area. The force of the arc pushes the molten metal through the workpiece and severs the material. The current flowing in the column of plasma arc can be between 10 and 1000 Ampers, the diameter of the jet emerging from the nozzle ranges from several tenths of a milimetre to several milimetres, the temperature inside the jet from $15000 \mathrm{~K}$ to $30000 \mathrm{~K}$ (Buschow, 2001). The process of the plasma cutting of metal materials is based on a transferred arc, which means that an arc is established between a refractory electrode ( - pole ) and the piece to be cut $(+$ pole $)$. This highly rigid and extremely hot stream of plasma fuses the metal over its full thickness and ejects it outside the cut thanks to the plasma's very high velocity. The choice of gas depends on the thickness of the material that is to be cut and on other criteria such as the quality of cut, productivity and running costs. The major advantages of plasma cutting lie in the higher cutting performance and the narrower heat- affected zone, along with minimum heat input. Most significant impact to the machined surface roughness have factors of feed rate of plasma torch and plasma gas pressure (Mayers et al., 2002). Among other factors that are less important belongs diameter of nozzle and distance between nozzle mouth and material. From the experimental results it can be said, that for achieving higher quality of cut surface it is recommended to use higher pressures of plasma gas and appropriate feed rate of plasma torch. Influence of referred factor occurs in the material visible heat- affected zone (HAZ). HAZ width is defined as the width of a detectable microstructural change measured perpendicular to the cut edge face. HAZ width is only applicable to alloys that undergo microstructural changes during the heating and cooling cycle of the cutting operation HAZ varies with speed and power (Gajdoš et al., 2010). The extent of the HAZ in low steel is related to process variables, such as cut speed and power, as well as material thickness. HAZ (Hatala, 2008) is around diameter 0,4$0,7 \mathrm{~mm}$ depending on material thickness (Hatala et al., 2009). In autors (Jurko et al., 2009/10, Straka et al. 2008) was state influence on base material after machining too.

\section{EXPERIMENTAL PROCEDURE}

The aim of this paper was to investigation of microstructures changes mainly microhardness evaluation in place in the heat affected zone in beginning, middle and finishing area after plasma cutting, Fig. 1.

For tested material in diameter plate from thickness $5 \mathrm{~mm}$ was used construction alloyed fine grained steel S355J2G3 marked by the norm EN10025-93 with the following chemical composition: $0.2 \% \mathrm{C}, 1.6 \% \mathrm{Mn}, 0.55 \% \mathrm{Si}, 0.04 \% \mathrm{P}, 0.04 \% \mathrm{~S}$, $0.009 \% \mathrm{~N}$

Performed cutting were done with a high powered advanced HD 3070 cutting system.

Measurements and analysis were made on samples of each of three defined area. It was removed a small section from each cut sample. The section was placed in a metallographic mount, polished and etched to reveal details in the microstructure, which allow analysis of HAZ phase content and microhardness. Microhardness test was realized in line from cutting place after plasma beam aloof $0.05 \mathrm{~mm}$ and next step by step in range of $0.1 \mathrm{~mm}$ with $200 \mathrm{~g}$ weight and time load $10 \mathrm{~s}$.

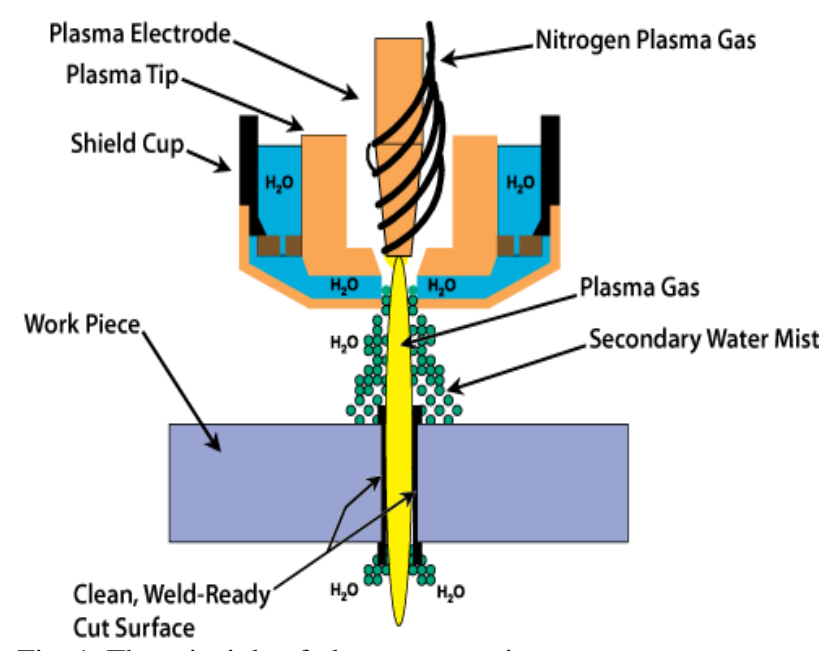

Fig. 1. The principle of plasma arc cutting

\section{RESULTS AND DISCUSSION}

\subsection{Microhardness evaluation of samples}

Investigations of microhardness are showing in fig.2. In all cases were values very higher in first places when compare with next measurements. In leading cut place it was value at 
270,3 HV0.2, middle cut place at $263 \mathrm{HV} 0.2$ and ending cut place at $277,8 \mathrm{HV} 0.2$. Values in HAZ heat affected zone gradually decreased to basic values of material in range from 144,4 till 165 HV0.2. From this follows, that HAZ in all measured areas is till $0.7 \mathrm{~mm}$ value. In leading and middle investigation place is comparable values, but in ending investigation place values were higher. It was state from the effect of accumulation of heat cutting process.

In Tab. 1 are showed percentage growth microhardness values from base material. Ending cut place were about 40,6\% which is lower as previous both investigation places, it was possible lower activity of beam of plasma.

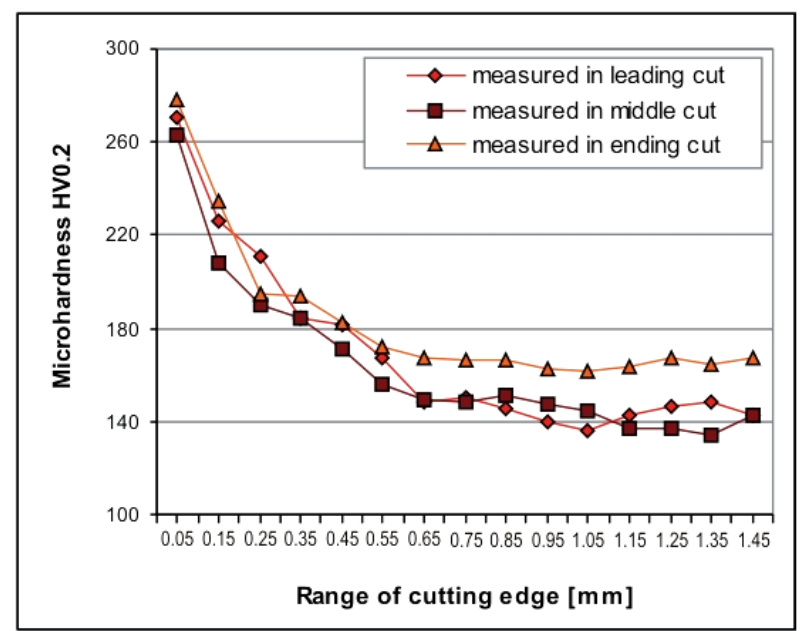

Fig. 2. Microhardness behaviour values in three measured area (leading, middle and ending cut place)

\begin{tabular}{|c|c|c|c|}
\hline \multirow{2}{*}{ Measured in: } & \multicolumn{2}{|c|}{ Range of cutting edge [mm] } & \multirow{2}{*}{$\begin{array}{c}\text { Percentage } \\
\text { growth from } \\
\text { base } \\
\text { material }\end{array}$} \\
\hline & 0,05 & $\begin{array}{l}\text { Average from 0,6 } \\
\text { (base material) }\end{array}$ & \\
\hline leading cut place & 270,3 & 144,4 & 46,6 \\
\hline middle cut place & 263,0 & 143,7 & 45,4 \\
\hline ending cut place & 277,8 & 165 & 40,6 \\
\hline
\end{tabular}

Tab. 1. Percentage growth microhardness values from base material

\subsection{Microstructure formation}

The microstructural damage zone (heat - affected area) is approximately 0,6 deep. The heat affected zone from a plasma cut is narrower and peak hardnesses are higher than that produced for example by flame cutting. Austenite formation is found to be complex while heated to a temperature $741{ }^{\circ} \mathrm{C}$ ( in between Ac1 and Ac3 temperatures ). The result of this show continued growth of austenite, passing the eutectoid temperature during cooling requires a radical change. Practically all the homogeneously dissolved carbon now has to go to the inhomogeneously distributed cementite - by diffusion. The austenite is quenched, i.e. rapidly cooled. The carbon stays in place - more or less- and this necessarily prevents pearlite and ferrite formation. Instead, a new lattice type is found, called "martensite". It's volume is getting down to the core of base material. HAZ goes through the narrow zone of normalization with fine - grained structure and considerably wider zone of partial pre - crystallization.Damaged created by a plasma torch cut - microstructure was originally a banded pearlite and ferite, $3 \%$ picral etch. Original magnification 50x.

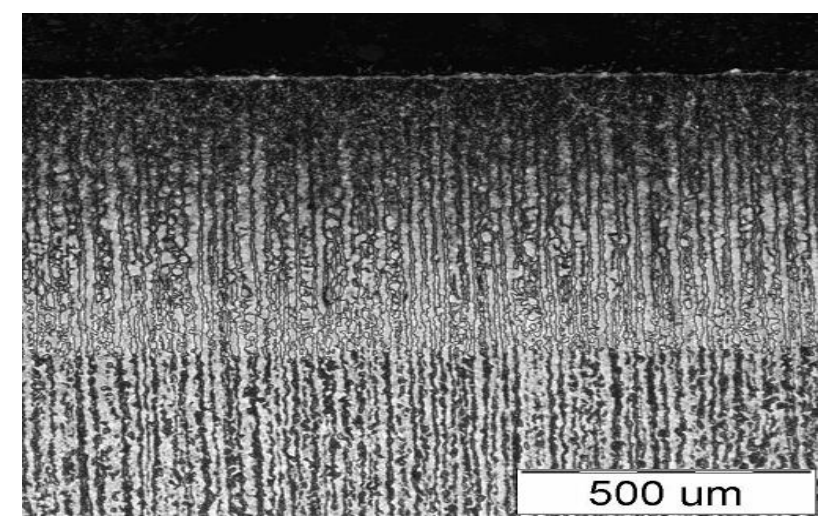

Fig. 3. The Picture of microstructure and HAZ (zoom $50 \mathrm{x}$ )

\section{CONCLUSION}

Following main results were obtained:

- Microhardness after plasma cutting decrease from original value from 40,6 till 46,6\% with comparisson from base material.

- HAZ heat- affected zone in our case was determined till 0.6 mm value.

- The place of leading and middle investigation area has compare values of microhardness, beside value of ending investigation place were higher at $165 \mathrm{HV} 0.2$ in base material. It is possible of higher accumulation from heat plasma cutting. - In microstructure investigation was visible change on martensite in HAZ.

\section{REFERENCES}

Buschow, J. (2001). Encyklopedia of materials: Science and technology, Elsevier, ISBN 0-08-043152-6, London

Gajdoš, M. et al. (2010) Temperature analysis of cutting tool and the machined surface at drilling of stainless steel. Acta Metallurgica Slovaca. Vol. 1 (April 2010), page numbers (357-361), ISSN 1338-1660

Hatala, M. (2008) Microstructure changes of constructional steel caused after thermal cutting with plasma arc. Scientific Bulletin. Vol. 22, serie C (2008), p. 207-210. - ISSN 12243264

Hatala, M.; Orlovský, I.; Mičko, M. (2009) Cutting process and microstructure changes of steel EN S355J0 caused after plasma arc cutting. Technologické inžinierstvo. Vol. 6, No. 2 (2009), page numbers (30-32), ISSN 1336-5967

Jurko, J.; Panda, A. (2009) Study of cutting zone machinability during the drilling of stainless steel Cr20Ni12Ti. Proceeding of MITECH 2009, Praha, ISBN 9788021319318, pp. 326-329, ČZU, Praha

Jurko, J. (2010) Study of changes a machined stainless steels surface during drilling. Annals of DAAAM for 2010 \& Proceedings of the 21th international DAAAM symposium. Vienna, ISSN 1726-9679, ISBN 978-3-901509-73-5, Katalinic, B. (Ed.) pp. 0051-0052

Mayers, A.; Ramtech. (2002). Encyklopedia of physical science and technology, Vol.12. Academic Press, ISBN 0-12227422-9, California, USA

Hloch, S; Valíček, J; Simkulet, V. (2009) Estimation of the smooth zone maximal depth at surfaces created by abrasive waterjet. International Journal of Surface Science and Engineering. Vol. 3, No. 4, (July 2009) page numbers (347359), ISSN 1749-785X

Straka, L. et al. (2008) Course of heat affected zone depth in the cross section sample after WEDM cutting, Journal of Engineering Annals of Faculty of Engineering Hunedoara. Vol. 6, No. 3, (Jun 2008), page numbers (232-236), ISSN 1584-2673 